\title{
Design and Construction of a Mobile Security Surveillance System with Wireless Data Transmission
}

\author{
${ }^{1}$ Aru, Okereke Eze,${ }^{2}$ Obia, Uchechukwu Stanley and ${ }^{3}$ Ihekweaba, Gozie \\ Department of Computer Engineering Michael Okpara University of Agriculture, Umudike, Umuahia, Abia \\ State, Nigeria
}

\begin{abstract}
The microcontroller based portable image acquisition and wireless data transmission is a security surveillance device. This can be used in monitoring of an area for effective image capturing and image data transmission. It combines the effectual hardware and software components and brings an output through blinking bulb and there is also a buzzer alarm if the system detects any image. Finally, it bridges the gap between visitors, intruders and the host using surveillance device.
\end{abstract}

Keywords: Security, Surveillance, image, data, camera, transmitter, gates

\section{Introduction}

Electronic communication has turned the world into a global village. Security electronics is a very vital aspect of information and communication in technology. Portable image acquisition and wireless data transmission is very indispensable in security electronics and can be used for security surveillance with the following system, Remote spy, cameras, Remote circuit Television, Remote Intruder alarm, etc.

Owing to choice and trend, I have decided to embark on a project work in the design and construction of portable image acquisition and wireless data transmission.

This electronics system is realized with a microcontroller involving an optocoupler and an electronic eye arranged with the combination of cadium-sulphide photo cell coupled into a light source from a laser beam provided by the arrays of laser diode. A transmitter designed with a simple tune Class C Amplifier is interfaced into the logic circuit through a Schmitt trigger NAND-gate oscillator. The second part of the system is the receiver unit, usually configured with a simple FM receiver designed with a transistor self-oscillating mixer meant to simulate a heterodyne pattern of reception for a distortion free output. An ADC0804 is introduced to convert the analogue output to digital, and then a microcontroller is introduced containing a driving software written in Assembly language.

Finally, an audible alarm and a blinking AC red bulb and four light emitting diode are interfaced into the controller output. The entire system is design in such a manner that when the transmitter picks the image of an intruder at 100meters and above, a signal is received and processed and raises a digital output that is capable of activating an audible alarm and a blinking red AC bulb.

\section{Overview Of The System}

The microcontroller based portable image acquisition and wireless data transmission system is designed with a transmitter and receiver unit. The transmitter circuit is realized with 4 modules joined together to form a functional hardware. At the input is an optocoupler with an electronic eye arranged with the combination of cadium sulphide photocell (cds) coupled with light source from laser beam provided by arrays of laser diode all joint to a quad 2 schmitt trigger NAND gate control logic circuit

The second is a modulator circuit, modulating the process of varying some characteristics of periodic waves with external signals. This particular modulating circuit varies the frequency of the master oscillator (carrier) with the output of the buzzer preamplifier which functions as the modulating frequency generator. The oscillator is an electronic device used to generate a signal normally for the purpose of converting the signal to the derived frequency.

The third and final module is the RF (Radio Frequency) module. It is a simple time classic amplifier that amplifies the output of the modulator into the atmosphere via the antenna at the frequency of $98 \mathrm{MHz}$. a single transistor configuration is used to achieve the RF unit which comprises of the modulator circuit, oscillator, and the RF amplifier circuit.

The receiver unit is designed in 7 distinct modules, at the input is a tuned Radio Frequency receiver circuit designed with a simple tuned class $\mathrm{C}$ amplifier two $\pi$ - filters, a single diode demodulator and impedance matching transformer using intermediate frequency type. This module receives the incoming signal from the transmitter, amplifies it, demodulate the signal to a standard where it will be ideal for the analog to digital converter (ADC 0804) to adopt. The second module is the ADC 0804 Intel semiconductor. This particular building block converts the analog Tuned Radio frequency receiver into 8-bit parallel digital output. 
The third module is the 89C51 microcontroller. This particular IC is used to perform a micro program control achieved using a real time software written in assembly language usually embedded. Then the fourth is the LED display panel that display with the aid of the LED when the receiver receives signal at the military surveillance department. The fifth block is the logic gate encoder circuit, usually contains two Schmitt trigger NAND gate control logic and quad 2 schmitt trigger NAND gate oscillator. The sixth module is a transistor electromagnetic relay interface that drives the 60 watts $\mathrm{AC}$ red bulb. The seventh and the last is the transistor static switch and buzzer interface that beeps whenever the receiver signal from the transmitter and this particular circuit contains a single transistor switch driving a buzzer at the collector.

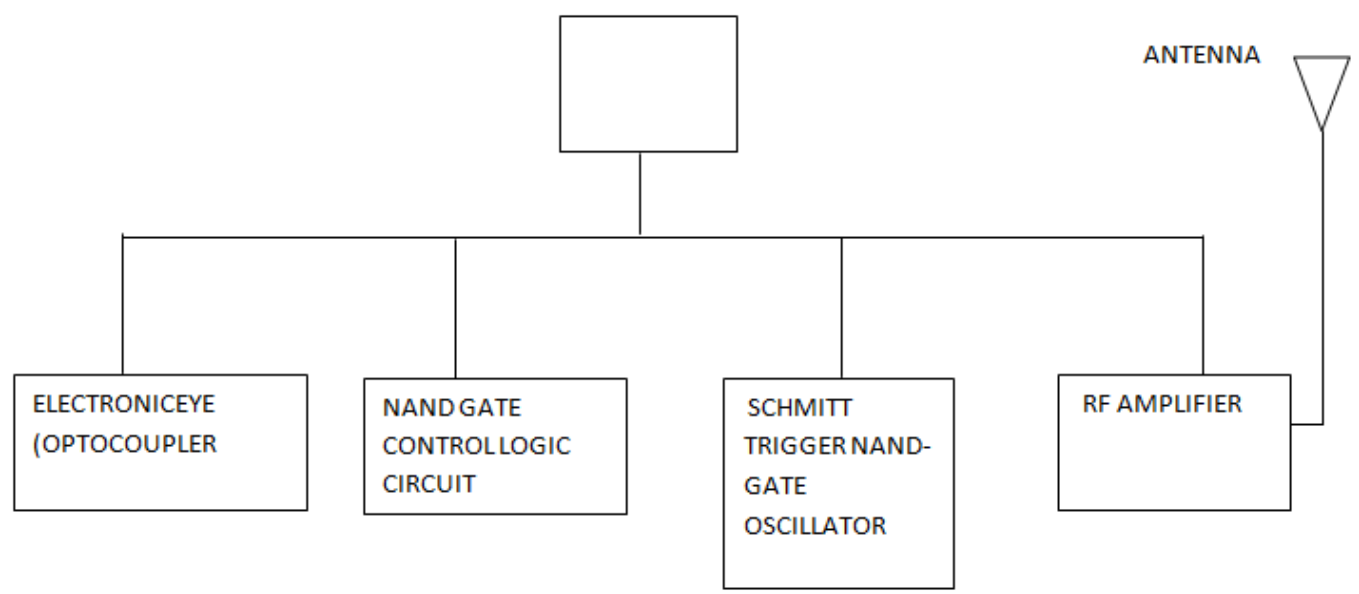

FIG. 1: Block Diagram Of The Transmitter

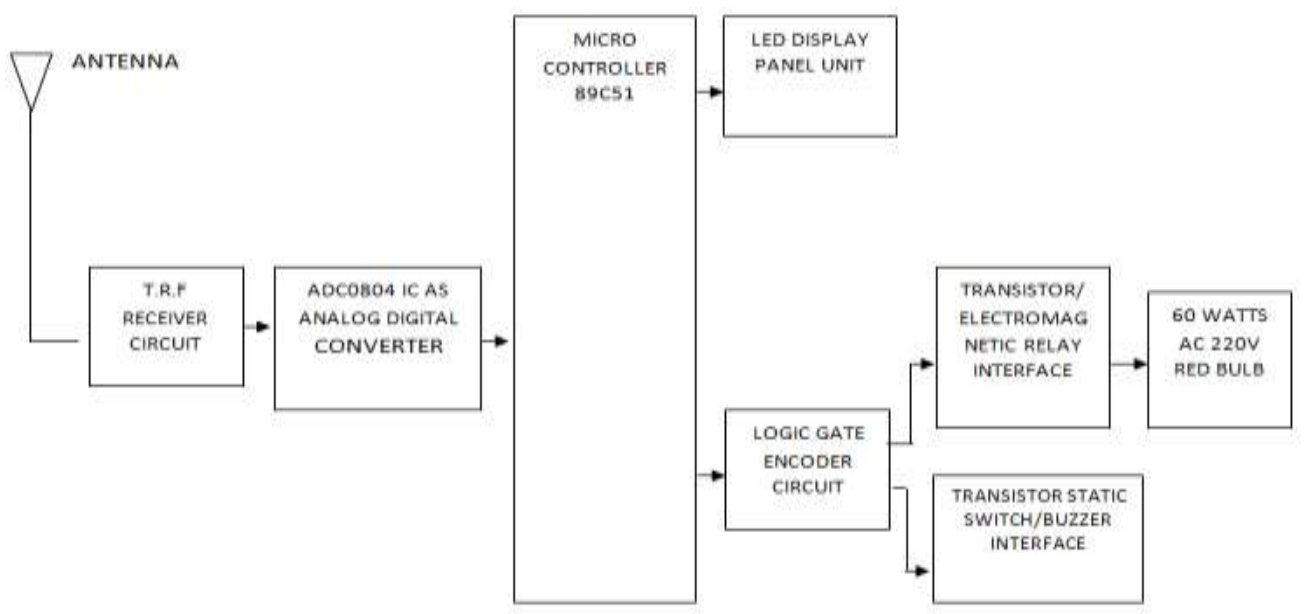

Fig. 2: Block Diagram Of The Receiver

\section{Operation Of The System}

Microcontroller based portable image acquisition and wireless data transmission system is used as a surveillance system and is designed with a transmitter and receiver units. At the input is an optocoupler that serves as an electronic eye realized with a combination of laser beam coupled into a cadium sulphide photocell. The IC1 74LS132 (quad 2 schmitt trigger NAND gate. The first two gate serve as a control logic while two other quad 2 schmitt trigger NAND gate serve as an oscillator that produces the pulse width modulator. This oscillator produces clock pulses that serve as the modulating frequency for the RF amplifier. $\mathrm{C}_{2}$ couples the output into the RF module. R6/R7 is a potential divider biasing resistor for $Q_{1}$. $Q_{1}$ is a tuned class $C$ amplifier. $\mathrm{Ra}$ is a temperature stability resistor for $\mathrm{Q}_{1}$. While $\mathrm{L}_{1} / \mathrm{C}_{\mathrm{v} 1}$ is a tank circuit that generates resonance effect. $\mathrm{C}_{4}$ couples the output of the tank circuit into the antenna and the antenna radiates the frequency of $90 \mathrm{MHZ}$ into the atmosphere.

The other part of the system is the receiver that receives signal from the transmitter. $\mathrm{C}_{1}, \mathrm{C}_{2}, \mathrm{C}_{3}$ are $\mathrm{T}$ capacitive networks that couples the incoming signal into $\mathrm{Q}_{1} \mathrm{RF}$ amplifier, while, $\mathrm{L}_{1}, \mathrm{C}_{4}$ and $\mathrm{R} 1$ are $\mathrm{S}$ impedence networks that bias $\mathrm{Q}_{1}$.

$\mathrm{C}_{\mathrm{v}} / \mathrm{L}_{2}$ is a tank circuit that receives the frequency of $90 \mathrm{MHZ}$ from the transmitter at resonance. $\mathrm{C}_{6}$ is a coupling capacitor that couples the output of the RF amplifier into the Trfilter realized with $\mathrm{C}_{7}, \mathrm{C}_{8}$ and $\mathrm{L}_{3}$. The 
Trnetwork is designed to reduce the overtone signal from the output of the RF amplifier. $\mathrm{L}_{4} / \mathrm{L}_{5}$ is an intermediate frequency transformer used for impedance marching. D1 is a demodular diode while $\mathrm{C}_{6} / \mathrm{C}_{10}$ and $\mathrm{L}_{6}$ are another Trnetwork and are the output of the demodular used to smoothen the output gain control. IC1 is an ADC (ADC0804 Intel semiconductor) containing $\mathrm{R}_{4} / \mathrm{C}_{14}$ frequency determining component. The $\mathrm{D}_{0}-\mathrm{D}_{7}$ from the ADC are fed into port 0 of the $89 \mathrm{C} 51$ microcontroller IC2, while the complementary data terminal of the ADC are fed into port 1 of the microcontroller. Pin 9 of the microcontroller contains automatic power-up reset realized with $\mathrm{R}_{2} / \mathrm{C}_{11}$, while pin $18 \& 19$ contains $12 \mathrm{MHZ}$ quad crystal that takes care of the frequency drift of the internal clock of the microcontroller. Four LEDs serve as a display usually interfaced with port 2 through $R_{6}-R_{9}$ current limiting resistors.

In other words, $\mathrm{Q}_{2}$ drives an electromagnetic relay which the 60 watts red bulb is connected to $220 \mathrm{~V}$ AC main supply also a buzzer is driven by the collector of $\mathrm{Q}_{3}$.

\section{Design Calculation}

Analog to Digital Converter (ADC 0804)

It is a TTL compatible. Therefore to find the value of $\mathrm{C} 4$, where the value of $\mathrm{F}$ (frequency) is $606 \mathrm{KHZ}$ and resistance $(\mathrm{R})$ is $10 \mathrm{k} \Omega$.

$\mathrm{F}=606 \mathrm{KHZ}, \mathrm{R}=10 \mathrm{~K} \Omega, \mathrm{C}=$ ?

Using

$$
\mathrm{F}=\frac{1}{1.1 \times \mathrm{RT} \text { xCT }}
$$

Substituting

$$
\begin{aligned}
& 606 \mathrm{KHZ}=\frac{1}{1.1 \times 10 \times 10^{3} \times C_{t}} \\
& 1=606 \times 10^{3} \times 1.1 \times 10 \times 10^{3} \mathrm{C}_{t} \\
& \mathrm{C}_{\mathrm{t}}=\frac{1}{606 \times 10^{3} \times 1.1 \times 10 \times 10^{3}} \\
& \mathrm{C}_{\mathrm{t}}=\frac{1}{6.666 \times 10^{9}} \\
& \mathrm{C}_{\mathrm{t}}=150 \mathrm{PF}\left(150 \times 10^{-12}\right)
\end{aligned}
$$

\section{For Buzzer Circuit}

$\mathrm{Q}_{10}=\mathrm{BC} 547$; Hfe $=100 \mathrm{~mA} ; \mathrm{IE} ; 80 \mathrm{~mA}$

$\mathrm{Hfe}=\mathrm{I}_{\mathrm{c}} / \mathrm{I}_{\mathrm{B}}$ (at saturation) also $\mathrm{Ic}=\mathrm{IE}=80 \mathrm{~mA}$

$100 \times 1 \mathrm{a}=80 \times 10^{-3}$

$$
1_{\mathrm{B}}=\frac{80 \times 10^{-3}}{100} \quad=0.0008 \mathrm{~A},
$$

$=4.3$

$$
0.0008=5.375 \times 10^{-3}=5.38 \mathrm{K \omega}
$$

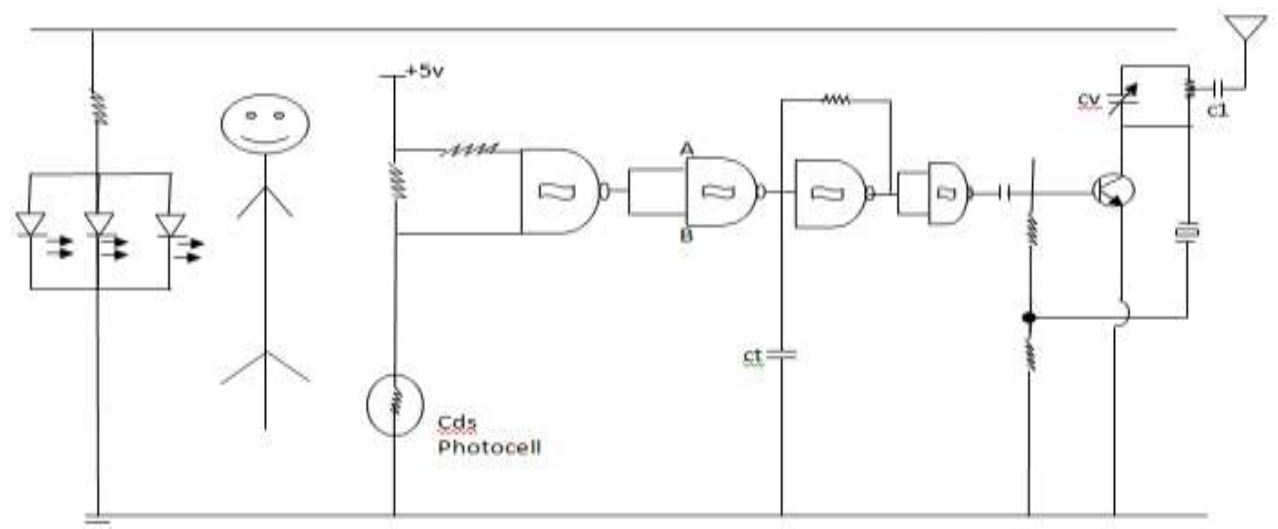

Fig. 4 : Circuit Diagram Of The Transmitter 


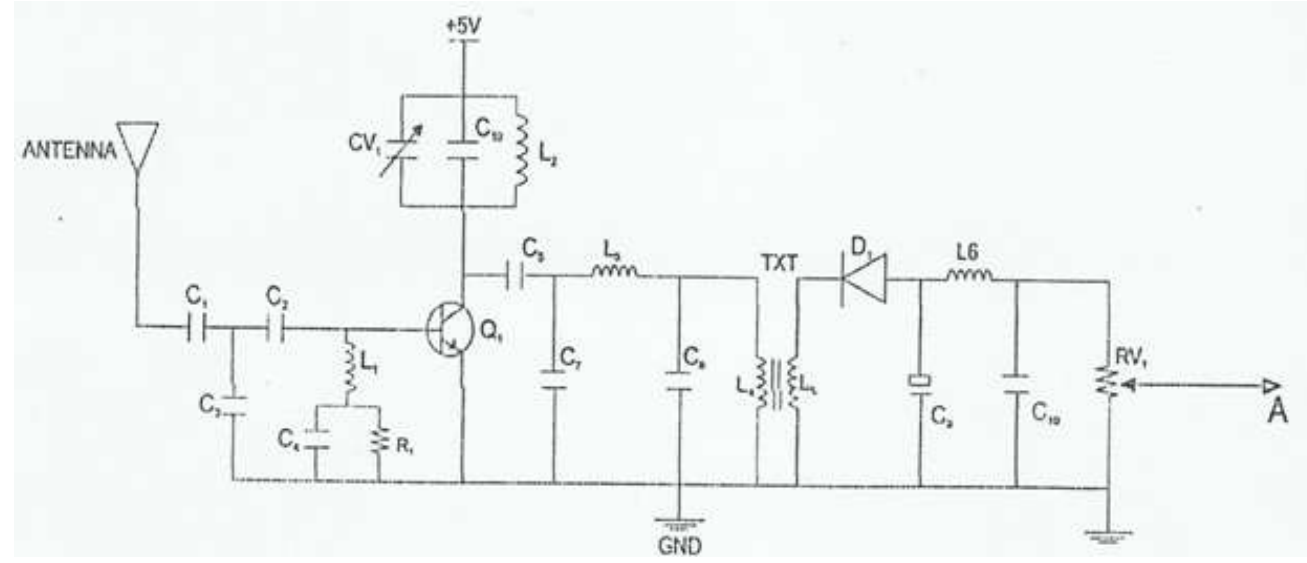

Fig.5 : Circuit Diagram Of Receiver

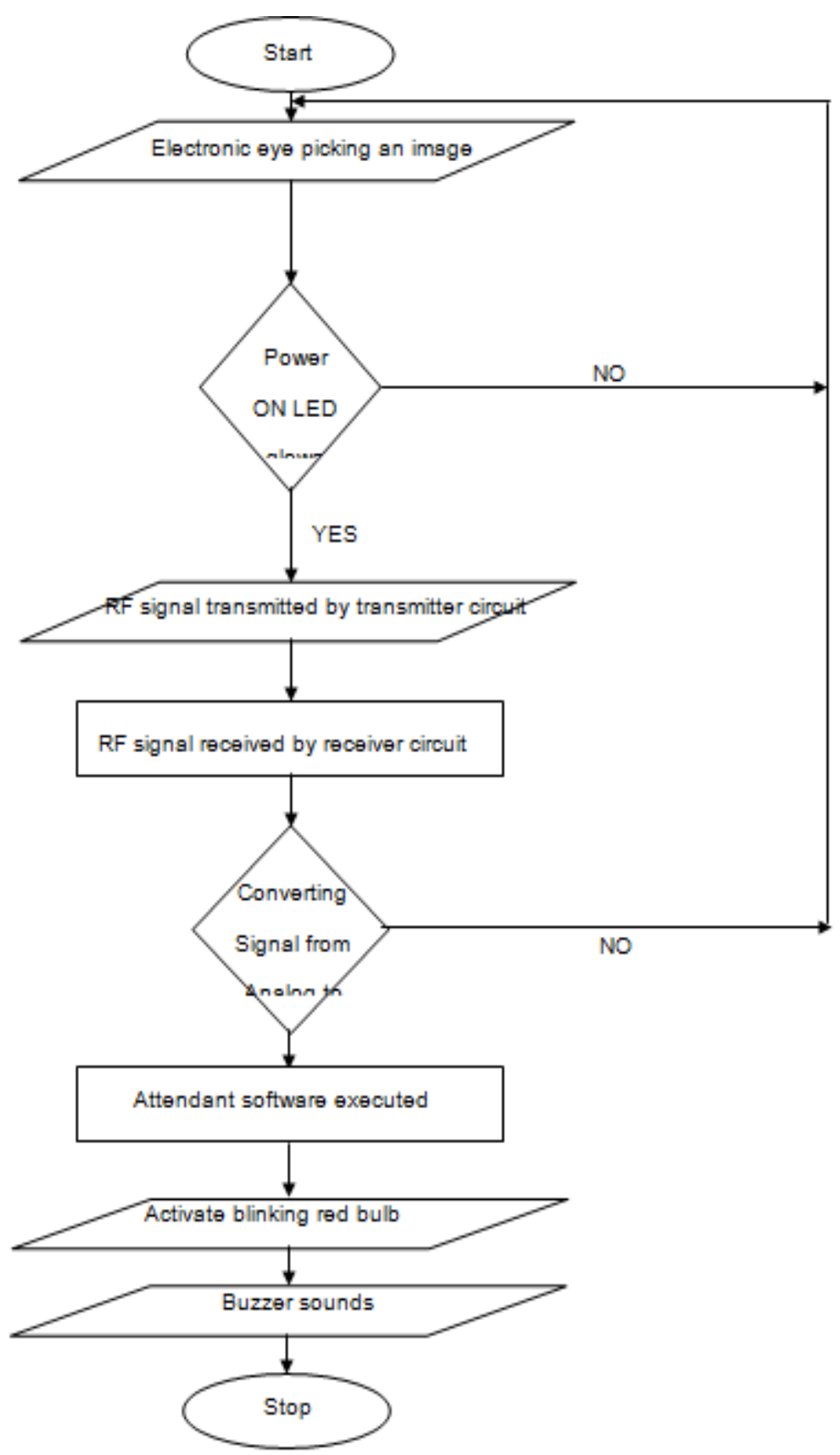

Fig.6: System Flowchart 


\section{Conclusion}

The need exists for a wireless security system because of the rate of insecurity in the world and Nigeria in particularly. Gone are the days when too many security personnel will be employed for mind a particular establishment mostly during close down hours. Also digital wireless security systems are very practical because they can be moved throughout the house/environment without having to receive anything, and in addition they are very cheap to construct. Various receivers can be mounted at some strategic locations in the house/establishment with one transmitter.

It is an object of the present innovation to provide a wireless transmitter and more particularly, a wireless digital security system, which is microcontroller based. This system is of very high precision and durability such that it can easily be marketed. In this present age, every organization needs the portable image acquisition and wireless data transmission system for bridging the link between intruders, buglers, visitor and the host.

\section{References}

[1] Dennis R. and John C. (2004), Electronic Communications $4^{\text {th }}$ edition, Push Print Services, New Delhi, India.

[2] Jacob, M. and Chritos, C. H. (1971): Integration Electronics, McGraw-Hill International Editions, New York, USA.

[3] Mehta V. K and Mehta R. (2005): Principles of Electronics, S. Chand and Company Ltd. New Delhi, India.

[4] Paul, H and Winfield, H (1995): The art of electronics, Longman, Los Angeles, USA.

[5] Theraja, B. L and Theraja, A. K (2004): a text of Electrical Technology, S. Chand and Company LTD, India.

[6] Tim, P : July edition (1987), Practical Electronics (Magazine).

[7] Brown, G: August edition (2004), Electronic trail blazers (Magazine).

[8] http:www.wikipedia.org/wiki/radio frequency wave band

[9] http:/www.wikipedia.org/wiki/transistor as a switch

Aru, Okereke Eze is a lecturer in the Department of Computer Engineering, Michael Okpara University of Agriculture, Umuahia, Abia State, Nigeria. His research Interests include Computer Hardware design and maintenance, digital systems design using microcontrollers and other computer related subjects.

Obia, Uchechukwu Stanley is a student in the Department of Computer Engineering, Michael Okpara University of Agriculture, Umuahia, Abia State, Nigeria. Her research interests include Computer Hardware design and maintenance, Security system design, expert systems etc.

Ihekweaba Goze is a senior Lecturer in the Department of Computer Engineering, Michael Okpara University of Agriculture, Umuahia, Abia State, Nigeria. His research interests include Computer Hardware design and maintenance, Security system design,Digital Communication , etc 